\title{
A family study of coeliac disease
}

\author{
T. J. DAVID* and A. B. AJDUKIEWICZ $\dagger$ \\ Bristol General Hospital, Bristol
}

\begin{abstract}
Summary. Thirteen of 141 cases $(9 \%)$ of overt, biopsy proven coeliac disease had a definitely affected relative. The pattern of inheritance in these families is compatible with an incompletely penetrant autosomal dominant gene. There was a female preponderance in the adults and the sporadic cases, but not in the children or the familial cases. The series included a pair of concordant and probably monozygotic twins. The authors believe that coeliac disease, as defined at present, is a heterogeneous condition.
\end{abstract}

The aetiology of coeliac disease is unknown, but the familial nature of the condition is well known and has prompted this and other studies (Thompson, 1951; Boyer and Andersen, 1956; Carter, Sheldon, and Walker, 1959; Gardiner, Mutton, and WalkerSmith, 1973). One major problem with a study of the inheritance of coeliac disease is usefully to define the condition. Gastroenterologists have not helped in the resolution of the genetics by introducing the peroral jejunal biopsy, and studies of patients and their relatives using this tool have produced conflicting results. On the one hand, MacDonald, Dobbins, and Rubin (1965) suggested that coeliac disease is inherited as an autosomal dominant with incomplete penetrance, while the view taken by Robinson et al (1971) is that the pathogenesis of coeliac disease is multifactorial, the genetic basis of susceptibility being polygenic. However, coeliac disease, or the future development of coeliac disease, cannot as far as we know be absolutely excluded by a normal jejunal biopsy. Furthermore, it is not known whether all patients with overt, biopsy proven coeliac disease have the same disorder.

Information from twin studies is sparse because most reports concerning coeliac disease in twins have either failed clearly to establish the zygosity or because the diagnosis has not been supported by jejunal biopsy. However, there are two reports of highly probable monozygotic twin pairs where discordance for coeliac disease has been proven (Hoff-

\footnotetext{
Received 17 April 1974.

* Present address: Bristol Maternity Hospital.

t Present address: Department of Medicine, Ahmadu Bello University Hospital, Zaria, Nigeria.
}

man, Wollaeger, and Greenberg, 1966; WalkerSmith, 1973).

Recently, it has been reported that there is an increased incidence of HL-A antigens 1 and 8 in adults and children with coeliac disease (Falchuk, Rogentine, and Strober, 1972; Stokes et al, 1972; McNeish, Nelson, and Mackintosh, 1973). This suggests that these particular antigens might influence an individual's susceptibility to coeliac disease, but does not resolve the genetic mechanisms that may be involved in the hereditary transmission the disease. This paper concerns a family study of patients with biopsy proven coeliac disease in the South West of England.

\section{Patients and methods}

All the patients were living in Bristol, Gloucestershire, or Somerset. The diagnosis of coeliac disease had been confirmed by the presence of subtotal villous atrophy in a jejunal biopsy. Careful family histories were taken, usually in the patient's home, and where it seemed possible that a relative might be affected the medical records of this relative were traced. Only relatives who had biopsy proven coeliac disease were taken as affected, and no attempt was made to biopsy relatives whether they had gastrointestinal symptoms or not. Thus, the study was confined to those with fully diagnosed overt coeliac disease.

\section{Results}

One hundred and twenty-eight out of 141 index patients $(91 \%)$ had no affected relatives. Thirteen out of $141(9 \%)$ had a positive family history of coeliac disease, with 21 affected relatives in all. 
Their pedigrees are shown in Fig. 1. The propositus marked on the pedigrees is the first member of each family to be affected (with the exception of family $E$ where this could not be established), but is not necessarily the index case by whom the family was ascertained. Of the 13 index cases with a positive family history, four ( $31 \%$ ) were children.

In five families (C, E, F, G, H) a parent and child only were affected. In four of these it was a mother and son, and in the fifth (family $\mathrm{H}$ ) a mother and daughter. The impression of sex-linkage is offset by the transmission from mother to daughter in family $\mathrm{H}$, as well as in families A and B. Vertical transmission through three generations is seen in family A.

In five families (I, J, K, L, M) only two sibs were affected. Four of these sib pairs were like sexed (two male, two female). There was one concordant set of female twins (in family $\mathrm{J}$ ) who were probably monozygotic and both of them had the following blood groups: A1, CDe/cde, Kell negative, Duffy positive, $P$ positive.

\section{Discussion}

Thirteen out of 141 index cases $(9 \%)$ of overt, biopsy proven coeliac disease had a definitely affected relative. This is a little higher than the $6 \%$ obtained by McCrae (1969) and the 5\% obtained by Robinson et al (1971), but lower than the $16 \%$ obtained by Mylotte et al (1972). Other series cannot be compared since the authors regarded anyone with an abnormal jejunal biopsy as having coeliac disease regardless of whether or not they were symptomatic.

Ninety-five out of 156 patients ( $61 \%$ ) were female, and this female preponderance has been noted in most previous studies. It does not apply if the children under 15 are studied separately, when 30 out of $57(53 \%)$ are female, but if the adults are

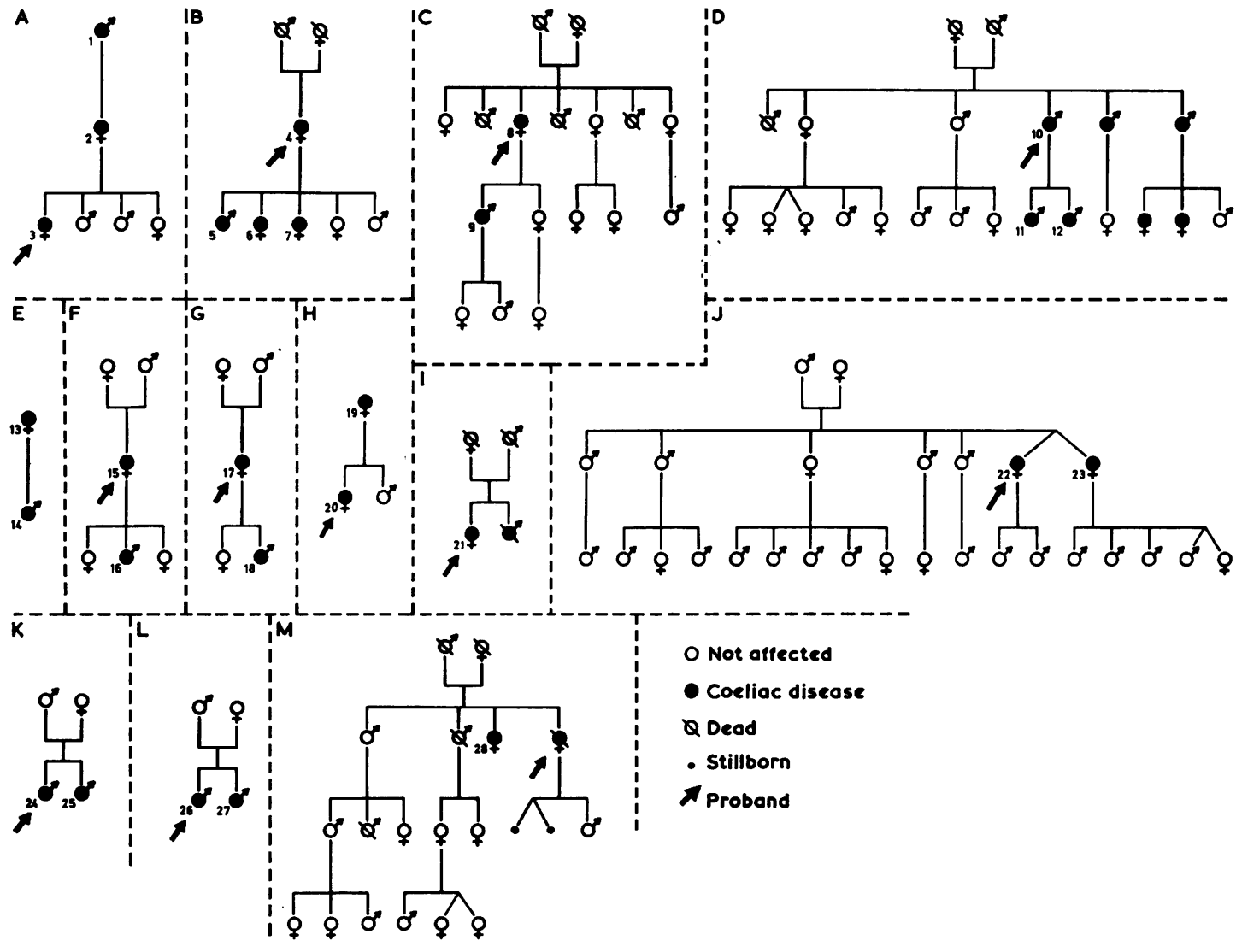

Fig. 1. Pedigrees of patients with coeliac disease. 
taken on their own then 65 out of $99(66 \%)$ are female. The predominance of females is hardly evident if the familial cases are taken alone (18 out of $34-53 \%$ ), but more impressive if the sporadic cases are taken alone ( 80 out of $128-62 \%$ ). Excluding the possibility of differential mortality, there are at least two reasons why adult women are more likely to get symptoms from coeliac disease than men. Firstly, menstruating adult women have greater iron requirements than men and are therefore more likely to present with iron deficiency, and second, coeliac disease is known to reduce fertility in women and may be a cause of recurrent abortions (Morris, Ajdukiewicz, and Read, 1970).

The pattern of inheritance in our families is compatible with an autosomal dominant gene with incomplete penetrance, as previously suggested by MacDonald et al (1965). This leaves the other 128 patients with no family history of coeliac disease to be explained. Whilst it is possible to account for all our results by invoking polygenic inheritance, or by an incompletely penetrant dominant gene, another explanation is that coeliac disease may well be a heterogeneous condition. A palmar dermatoglyphic study of patients with coeliac disease failed to reveal significant differences when the familial and sporadic cases were compared with controls (David and Ajdukiewicz, 1974), and this tends to support a single gene hypothesis for coeliac disease because single gene disorders do not affect the dermatoglyphics unless they have a prenatal influence on the developing limbs or a direct influence on ridge formation (David, 1972).

Of the patients $37 \%$ were children. Four of the $13(13 \%)$ familial cases were children. Thus a family history of coeliac disease did not appear more often in the relatives of 'early onset' patients. Taking early onset as an index of severity, this result fails to support polygenic inheritance. However, this approach is open to question. Not only is childhood onset not necessarily an index of severe disease, but this approach ignores adults with coeliac disease in whom the disease was quite obviously present in childhood.

If we arrive at the hypothesis that the familial cases of coeliac disease are the result of an incompletely penetrant dominant gene, certain problems arise. In the light of the alleged population frequency of the disease ( 1 in 1850 in Scotland; McCrae, 1969-and 1 in 303 in Ireland; Mylotte et al, 1973) and if say $9 \%$ of cases are due to a dominant gene, for a relatively detrimental disease this is an unduly high frequency. To accept this explanation it would be necessary to postulate either (1) that the $9 \%$ of cases represent the action of several dif- ferent genes-ie, genetic heterogeneity, or (2) that the gene is acting 'recessively' and has reached polymorphic, or almost polymorphic levels because it is relatively advantageous; and that it has become 'dominant' only recently as a disease of, for example, civilization.

Coeliac disease could be a single disease entity caused by a common recessive gene which requires some environmental factor for the disease to be manifested. Such a model exists in the emphysema which results from a combination of homozygosity for the $\mathrm{Z}$ allele at the $P i$ locus plus cigarette smoking, and where the $Z$ gene is so common that dominant inheritance is mimicked in some families (Kumar et al, 1974). Indeed, coeliac disease has been regarded by some (Burman, 1964; Townley, 1973) as an inborn error of metabolism inherited as an autosomal recessive, though this is doubted by others (Frézal and Rey, 1970), and is not easily reconciled with the HL-A antigen data.

In conclusion, in coeliac disease we may be dealing with many possibilities which include a dominant gene with incomplete penetrance, a common recessive gene requiring an environmental factor for the disease to appear in homozygotes, polygenic or multifactorial inheritance, or multiple causation with forms inherited in various ways. We favour the notion that coeliac disease, as defined at present is a heterogeneous condition.

We are indebted to the many physicians who permitted us to study their patients, and to Professor A. E. A. Read and Professor P. E. Polani for their most helpful comments.

\section{REFERENCES}

Boyer, P. H. and Andersen, D. H. (1956). A genetic study of celiac disease. American Fournal of Diseases of Children, 91, 131-137.

Burman, D. (1964). Celiac disease: II. Its relationship to wheat. Clinical Pediatrics, 3, 5-10.

Carter, C., Sheldon, W., and Walker, C. (1959). The inheritance of coeliac disease. Annals of Human Genetics, 23, 266-278.

David, T. J. (1972). Palmar dermatoglyphs in tuberous sclerosis. fournal of Medical Genetics, 9, 443-447.

David, T. J. and Ajdukiewicz, A. B. (1974). Palmar dermatoglyphs in celiac sprue. In Dermatoglyphics-An International Perspective, ed. by J. Mavalwala. Mouton, The Netherlands.

Falchuk, Z. M., Rogentine, G. N., and Strober, W. (1972). Predominance of histocompatibility antigen $\mathrm{HL}-\mathrm{A} 8$ in patients with gluten-sensitive enteropathy. Fournal of Clinical Investigation, 51, 1602-1605.

Frézal, J. and Rey, J. (1970). Genetics of disorders of intestinal digestion and absorption. In Advances in Human Genetics, vol. 1, ed. by H. Harris and K. Hirschhorn, pp. 275-336. Plenum, New York.

Gardiner, A. J., Mutton, K. J., and Walker-Smith, J. A. (1973). A family study of coeliac disease. Australian Paediatric fournal, 9, 18-24.

Hoffman, H. N., Wollaeger, E. E., and Greenberg, E. (1966). Discordance for nontropical sprue (adult celiac disease) in a monozygotic twin pair. Gastroenterology, 51, 36-42.

Kumar, P., Lancaster-Smith, M., Cook, P., Stansfield, A., Clark, M. L., and Dawson, A. M. (1974). $\alpha_{1}$ antitrypsin deficiency in chronic liver disease, and a report of cirrhosis and emphysema in adult members of a family. British Medical fournal, 1, 366-367. 
McCrae, W. M. (1969). Inheritance of coeliac disease. Fournal of Medical Genetics, 6, 129-131.

MacDonald, W. C., Dobbins, W. O., and Rubin, C. E. (1965). Studies of the familial nature of celiac sprue using biopsy of the small intestine. New England fournal of Medicine, 272, 448-456.

McNeish, A. S., Nelson, R., and Mackintosh, P. (1973). H-LA 1 and 8 in childhood coeliac disease. Lancet, 1, 668

Morris, J. S., Ajdukiewicz, A. B., and Read, A. E. (1970). Coeliac infertility: an indication for dietary gluten restriction? Lancet, 1, 213-214.

Mylotte, M., Egan-Mitchell, B., Fottrell, P. F., McNicholl, B., and McCarthy, C. F. (1972). Familial Coeliac Disease. Paper read at the Annual Meeting of the Association of Physicians, Royal College of Physicians, London, 24 March.

Mylotte, M., Egan-Mitchell, B., McCarthy, C. F., and McNicholl,
B. (1973). Incidence of coeliac disease in the west of Ireland. British Medical fournal, 1, 703-705.

Robinson, D. C., Watson, A. J., Wyatt, E. H., Marks, J. M., and Roberts, D. F. (1971). Incidence of small-intestinal mucosal abnormalities and of clinical coeliac disease in the relatives of children with coeliac disease. Gut, 12, 789-793.

Stokes, P. L., Asquith, P., Holmes, G. K. T., Mackintosh, P., and Cooke, W. T. (1972). Histocompatibility antigens associated with adult coeliac disease. Lancet, 2, 162-164.

Thompson, M. W. (1951). Heredity, maternal age, and birth order in the etiology of celiac disease. American fournal of Human Genetics, 3, 159-166.

Townley, R. R. W. (1973). Celiac disease-an inborn error of metabolism. American fournal of Digestive Diseases, 18, 797-800.

Walker-Smith, J. A. (1973). Discordance for childhood coeliac disease in monozygotic twins. Gut, 14, 374-375. 